\title{
Difficulties encountered in care for elderly persons with dementia: coping based on participatory research
}

Barbara Martins Corrêa da Silva'

Célia Pereira Caldas²

Helena Maria Shchelowski Leal David²

Michel Jean Marie Thiollent, 3

Abstract

Objective: to analyze the proposal of an action plan created by nurses to deal with difficulties in caring for the elderly. The aim of the present study was therefore to analyze the difficulties that family caregivers find in relation to access to services, material resources and the support network when meeting the care needs of the elderly in accordance with Brazilian public policy. Method: the methodology of participatory research and content analysis proposed by Bardin was used. The context was the Geriatric service of a university hospital. The group of co-researchers included eight nurses and 12 caregivers of elderly people with dementia. Results: the following categories emerged from the analysis: contradictions and work proposals. The contradictions category revealed reflections about the difference between the proposed care for the elderly and the reality of a lack of care and the precarious conditions of health services. This situation leads to overburdening of caregivers. The work proposals refer to the strategies used by nurses to establish a relationship of support to family caregivers to cope with the difficulties involved in care for the elderly. Conclusion: nurses recognize that they are professionals capable of receiving, listening to and managing the needs of family caregivers of the elderly, thus promoting the health of the elderly and the caregivers themselves, preparing the family of the patient for home care and coping with difficulties experienced in elderly care.

Keywords: Caregivers. Health Services. Social Conditions.

\footnotetext{
Universidade do Estado do Rio de Janeiro (UERJ), Faculdade de Enfermagem, Programa de Pós-graduação em Enfermagem. Rio de Janeiro, RJ, Brasil.

2 Universidade do Estado do Rio de Janeiro (UERJ), Faculdade de Enfermagem, Departamento de Enfermagem de Saúde Pública. Rio de Janeiro, RJ, Brasil.

3 Universidade do Grande Rio, Faculdade de Administração, Programa de Pós-graduação em Administração (PPGA). Rio de Janeiro, RJ, Brasil.
} 


\section{INTRODUCTION}

It is known that family caregivers require special attention from health professionals who deal with the elderly. However, a degree of illness and burden has been perceived among caregivers. The relationship between caregiver-elderly person and the health professional, meanwhile, often involves conflict. Treatment strategies should therefore not be implemented vertically and the bond, affectivity, availability and willingness to care of the social actors involved should be considered.

With this in mind, the present study describes an action plan created together with nurses and family caregivers of the elderly, highlighting the value of social participation in strengthening the Brazilian Unified Health System (SUS) ${ }^{1}$.

The SUS does not yet guarantee effective social participation ${ }^{2}$ through the vocalization of needs and knowledge. Thus, the promotion of dialogue between nurses and caregivers through the Caring for Caregivers workshops can lead to reflections, an exchange of experiences on health, the renewal of life projects and the overcoming of challenges.

The theoretical reference that converged with the research proposal was the "theory of social production of the health-disease process", which in turn explains the political, economic and social determinants of health and disease distribution in rural areas and in societies, identifying the protective and harmful aspects for health present in the social organization ${ }^{3}$.

Despite the constitutional guarantee of a universal public health system for the Brazilian population ${ }^{4}$, there are no provisions in SUS that support the daily activity of family care. Feeling love and affection for elderly persons is not always enough to provide adequate and quality care, as specific and necessary conditions are involved in adapting homes for the demands of care and acquiring the necessary technology ${ }^{5}$.

There is also often a divergence between how much care the elderly person requires and how much the caregiver is able to provide. As the elderly individual becomes more dependent, so caregivers are required to devote more of their time to care, often to the detriment of caring for themselves. Cupidi et al. ${ }^{6}$ states that an increase in the degree of dependency of the elderly person negatively and progressively impacts the health of caregivers, who may exhibit symptoms of depression and other neuropsychiatric disorders.

It is therefore important to understand that family care is influenced by a person's culture, values and life history ${ }^{7}$, with a subsequent positive or negative impact on the health of those involved ${ }^{8}$. Thus, when considering the family as an integral part of the process of caring for the elderly, it is fundamental to understand and care for it as a complex social unit with its own needs? When health professionals seek to understand the individual within the logic of their life course and historicity, care can be planned realistically within the scope of the family and the health service ${ }^{10}$. This practice is challenging, however, as it is difficult to integrate personal involvement and productivity and resolutivity ${ }^{11}$.

Mendes, Pazzato and Sacado ${ }^{12}$ argue that encouraging dialogue and interaction can lead to the production of health.

The objective of the present study is to analyze the proposal of an action plan elaborated by nurses to tackle difficulties in the care process of the elderly.

\section{METHOD}

The participatory research methodology was used to construct an action plan prepared in conjunction with a team of nurses, based on their participation in workshops with caregivers of the elderly. This method allows participating researchers to coordinate group work activities and decide on the goals and means required to produce a particular product or service ${ }^{13}$.

The present study was performed in the outpatient clinic of the University Hospital of the Universidade do Estado do Rio de Janeiro, and data collection occurred between July 2015 and March 2016. The participants were eight nurses from this health service and 12 caregivers of elderly people with dementia who accompanied them to the clinic. The inclusion criterion for the nurses was to have worked in the 
health service for a period of $\geq 6$ months, while the inclusion criterion for the caregivers was to have been responsible for the care of the elderly for at least six months. The invitation to participate in the workshops was given to family caregivers who accompanied the elderly persons in the waiting room or during the nursing consultation at the geriatric outpatient clinic. All caregivers who met the inclusion criteria and who attended the workshops were selected.

The decision to involve nurses was due to the fact that care is the central aspect in the work process of this category of professionals. In addition, the historical and contradictory relationship between home care, which is produced in the sphere of the reproduction of life, privately, and through social reproduction, and professional care, which today takes place in the public sphere.

After authorization from the coordinators, a meeting was held with the nursing team to form the research group. When discussing the study design with the team the idea of holding workshops for caregivers emerged, with the theme: Caring for Caregivers. The team was involved in the dissemination of the project and in inviting caregivers to attend the outpatient clinic. Four workshop sessions were held, one per month, as part of the pre-existing activities of the group of caregivers at the service.

Workshop 1 How is your health? had nine participants, of whom three were nurses and six were caregivers. The theme of Workshop 2 was Rebuilding life projects. It had 13 participants, namely three nurses, one nursing student, one psychologist and eight caregivers. The theme of Workshop 3 was Look after your back! and it had 11 participants of whom four were nurses, one was a nursing student and six were caregivers. The theme of Workshop 4 was Overcoming challenges, and it involved 11 participants - three nurses, one nursing student, one occupational therapist and six caregivers. Although the number of participants varied in each workshop, this difference did not affect the development of the theme in the group.
At the end of the four workshops with the caregivers, the content that had emerged was analyzed. The results of this analysis were discussed with nurses at two meetings.

The discourses were recorded, transcribed and analyzed using the Bardin content analysis method ${ }^{14}$ at each stage of data collection (in workshops and in the meetings with nurses). The meetings were mediated through a data collection script that served as an investigative tool and contained questions regarding the care needs of the elderly, contradictions between the care that the individual considers ideal and that which is implemented, and proposals to overcome such contradictions. As an end product, an Action Plan was elaborated that concretized the results of this study.

The present study was submitted to the Research Ethics Committee of the Hospital Universitário Pedro Ernesto and approved under number CAAE 4449901520005282. All the co-researchers signed a Free and Informed Consent Form in accordance with the guidelines for research involving human beings ${ }^{15}$.

\section{RESULTS}

The sociodemographic characteristics of the group of elderly caregivers are shown in Table 1.

Of the eight participating nurses, six were female and two were male, while their age ranged from 22 to 60 years. Regarding the time of service, one nurse had worked in the service for 12 years, four for two years, two for one year and one for six months. Two had nursing doctorates, one had a master's degree in nursing, four were nursing residents, and one had an undergraduate nursing degree.

Table 2 below shows the quantity of the Registration Units (RU) that led to the construction of the themes and from these, the construction of the categories that emerged from the analysis of the discourse of the nurses. 
Table 1. Sociodemographic characteristics of family caregivers of elderly persons. Rio de Janeiro, Brazil, 2017.

\begin{tabular}{|c|c|}
\hline Variables & $\mathrm{n}(\%)$ \\
\hline \multicolumn{2}{|l|}{ Age } \\
\hline $59-70$ & $10(83.33 \%)$ \\
\hline $71-84$ & $2(16.67 \%)$ \\
\hline \multicolumn{2}{|l|}{ Gender } \\
\hline Female & $8(66.67 \%)$ \\
\hline Male & $4(33.33 \%)$ \\
\hline \multicolumn{2}{|l|}{ Marital status } \\
\hline Without partner & $5(41.67 \%)$ \\
\hline With partner & $7(58.33 \%)$ \\
\hline \multicolumn{2}{|l|}{ Family Income (in reais) } \\
\hline$\leq 3,000.00$ & $6(50 \%)$ \\
\hline $3,000.00$ to $7,000.00$ & $5(41.67 \%)$ \\
\hline$\geq 7000.00$ & $1(8.33 \%)$ \\
\hline \multicolumn{2}{|l|}{ Occupation } \\
\hline Doesn't work outside home & $10(83.33 \%)$ \\
\hline Works & $2(16.67 \%)$ \\
\hline \multicolumn{2}{|l|}{ Schooling (years of study) } \\
\hline$\leq 20$ & $4(33.33 \%)$ \\
\hline$>20$ & $8(66.67 \%)$ \\
\hline \multicolumn{2}{|c|}{ Degree of kinship with elderly person } \\
\hline Spouse & $3(25 \%)$ \\
\hline Son & $5(41.67 \%)$ \\
\hline Son-in-law/daughter-in-law & $4(33.33 \%)$ \\
\hline Total & 12 \\
\hline
\end{tabular}

Table created by authors.

Table 2. Subcategories and categories of discourse of nurses. Rio de Janeiro, Brazil, 2017.

\begin{tabular}{llll}
\hline Subcategories & RU/subcategory & Categories & RU/Category \\
\hline The contradictions experienced by family & 22 & Contradictions & 36 \\
caregivers & 14 & & \\
\cline { 2 - 3 } The contradictions of the public health system & 21 & Work proposals & 71 \\
Listening & 20 & \\
Resolutive capacity & 20 & \\
New Strategies & 10 & \\
Positive experiences &
\end{tabular}




\section{Category: contradictions}

The main contradiction that the nurses highlighted in the discourse of the caregivers refers to intergenerational conflicts. In the discourse below, which was highlighted by a nurse, a caregiver projects her own future based on the care she gives her mother today:

"My daughter said to me 'let my grandmother go'. I found it aggressive, I didn't understand. Then my other daughter explained: "She told you not to be so worried about the future, let things go with the flow. I found it kind of grotesque" (caregiver 5).

The nurse then analyzed the discourse of the caregiver:

"This one about the daughter telling her mother who takes care of her grandmother to stop doing it, I saw it in other discourses. I thought: how does this sandwich generation, the daughter of the elderly person who is between her mother and her daughter, plan the future... to what extent does she project: I will take care of my mother and my daughter will take care of me. I care for her the way I would like to be cared for, I respect her because I learnt it this way, I take care of her because I learned to care for my parents. So here she is projecting." (nurse 1).

"Virtuous is not staying at home taking care of someone, virtuous is to have a master's, a doctorate. Concepts have changed" (nurse 1).

The nurse's account of what she considers as "virtuous" seems to refer to professional attributes, highlighting the devaluation of domestic work in today's society, placing responsibility on the individual to resolve the conflict between the demands of society and delivering a minimum quality of $\operatorname{care}^{16}$.

Regarding the contradictions within the public health system, Longhi and Canton ${ }^{17}$ analyzed the contradictions relating to the concept of citizenship among SUS users and concluded: we are undergoing a credibility crisis in Brazilian society, with a discredited political class ${ }^{17}$. This finding corroborates the results of the present study, which can be seen in the following discourse:

\begin{abstract}
“There are many contradictions. We are a referral center, but we have problems with physical space, a limited number of health professionals, we should have more time to carry out activities that required less intensive technology, such as cognitive stimulation. The biggest contradiction is that we are part of a university and a university hospital that says that it is a friend of the elderly, but there is no focus on them, no valorization, no incentive, no prioritizing." (nurse 1).
\end{abstract}

Correlating the findings with the "social production theory", the contradictions of the public health system lead to conflicts for caregivers, as the scarcity of financial resources is a factor makes caring for the elderly difficult ${ }^{3}$. Such a situation must be understood in the light of cyclical crises of capital accumulation. This dynamic affects the health sector, and difficulties in accessing services penalize those social groups that have historically suffered the effects of the profound inequality of our social order more severely ${ }^{3}$.

It is therefore inferred that there is a conversion of biological facts into collective actions and health is influenced by environment and epidemiological issues $^{12}$. In other words, problems of social well-being are not simply technical issues, and the contradictions of the public health system have an impact on the quality of life of the caregiver ${ }^{18}$.

Therefore, health is the result of a process involving different dimensions of living conditions and the social contexts in which social groups exist ${ }^{19}$.

It is therefore important for the family to define the areas in which the health team can help and what needs should be met and to prioritize interventions. This can be seen in the following discourse relating to strategy and the need for the elderly to be linked to professionals:

"It's difficult because we're in a teaching hospital, but it's upsetting to have so many health professionals around the world complaining about disease, a lack of money, dependence, a lack of family structure..." (Nurse 4). 
One way to reduce the contradictions of the Public Health system is the proposal to consolidate the National Humanization Policy (NHP) within the SUS. This represents a system of institutional support and a device used for the implantation of a more receptive structure in health services ${ }^{20}$. The NHP proposal seeks new ways of operating, functioning, acting and producing organizations, considering the assumptions of institutional democracy and autonomy ${ }^{20}$.

\section{Category: Work proposals}

This category was constructed from the following themes: listening, resolutive capacity, new strategies and positive experiences.

Listening is a low-intensity technology, cited in the NHP as a device to tackle the daily impasses in the network and in health services, as well as improving the access of the users to the health system $^{20}$. From this perspective, it was observed that the nurses are aware of the NHP and are capable of self-criticism regarding their own application of the principles of this policy:

\begin{abstract}
"I value the caregiver's actions first and foremost: 'your relative is really well cared for.' So when he says, 'I can't, I can't do it,' I say, do as much as you can because we know you're doing your best, because we know that there is love there even when it doesn't seem like it, even when the family are fighting. But we are very afraid of being mawkish, of being misinterpreted." (nurse 7).
\end{abstract}

Here the importance of active listening and reception is made explicit. When a caregiver opens up, talks about their difficulties and the health professional accepts this without judgment, a bond is established, which can guarantee adherence to guidelines.

According to the current trend, the concept of care acquires a social, anthropological, historical and ethical dimension, becoming an object of interdisciplinary research ${ }^{21}$. It is important to note that this type of care requires an interpersonal relationship, known as "accompaniment". The notion of accompaniment moves away from the idea of control (guidance) and opens space for a posture of more subjectivity and autonomy. In this way, if accompaniment is no longer guiding, the companion ceases to have absolute authority and so diminishes the anxiety of always being right ${ }^{21}$. But it is not always so. Self-criticism can be seen in the following discourse:

"I often see myself as just one more person making demands. Then instead of walking away lighter, the other person ends up feeling more weighed down. The responsibility is too much for the caregiver. And sometimes these are problems that we can't solve, such as money problems." (nurse 4).

"We have to stop being the patient's boss, drowning them in information, we have to stop being so cartesian and provide a helping relationship. And the rest will come." (nurse 7).

In view of these testimonies, it can be seen that the participating researchers recognize the importance of reception when listening to the user and in this unit, as in other units of the SUS, reception is used as a strategy for screening needs. However, it is important to note that reception is not a neutral space and is often seen as a form of alleviating deficiencies in the responsiveness of services.

The discourse of the nurse below points to a vision that values the potential of reception as a strategy of care management and not just a device for the pacification of the user in their quest for resolution:

"I think we need to stratify demand. We have to identify those with needs and listen to them" (nurse 1).

The participants emphasized the importance of a professional capable of receiving, listening and managing demands. After all, nurses should be available to those accompanying the elderly, reinforcing the care guidelines so that they become safer ${ }^{22}$.

Regarding the theme of "resolutive capacity", participants cited actions such as: empowering family 
care, using resources assertively, and strengthening positive experiences as examples of strategies for achieving resolution. Statements in which the nurses emphasized the importance of practice based on the management of care through decision-making in a multi-professional team and the establishment of personal bonds between the users and the professionals are highlighted:

\footnotetext{
"We know it's not new: the rounds, the end-ofshift meetings, it's a different approach that adds a lot." (nurse 7).

"We tried to do this, try to always schedule the follow-up appointments with the same health professional and the results were very positive" (nurse 2).
}

It is the recognition of the importance of interdisciplinarity and the establishment of bonds. It is the understanding of demand as a process that is produced, not natural, the understanding of subjectivity as production, the perspective that you learn about reality through intervention ${ }^{20}$.

The participants emphasized that these strategies are important to prevent such contradictory situations, which may become iatrogenic, as explained in the following discourse:

"Another appointment and another professional saying the complete opposite. The advice of one doctor contradicted the other". (nurse 3).

The need to discuss the Therapeutic Plan in a multi-professional team and for the personalized service of the user by the same professionals to guarantee a bond and coherence is therefore clear.

Far from limiting one's gaze to a fixed, established reality, it aims to expand our conception of the world, including the moveable plane of the reality of the services that coexist within what is already instituted ${ }^{20}$.

This involves permanent tension between the needs of the elderly and those of each member of the family $^{23}$, and nurses can help reduce these tensions when seeking a practice committed to integrality, promoting dignified care for the elderly ${ }^{22}$.

The analysis of the categories that emerged from the discourse of the nurses and caregivers allowed the creation of the action plan, shown in figure 1:

- To value listening;

- Perform more inter-consultations;

- Define the demand for nursing care within the team;

- Use the area of the nursing consultation as a space for exchange;

- Stimulate the co-responsibility of the caregiver and the elderly person as a strategy to achieve adherence;

- Agree the guidelines,

- Avoid contradictions between professionals through consultation and team meetings to agree on actions;

- Perform activities of cognitive stimulation and day-center activities;

- Incorporate the workshop strategy as an activity of the Elderly Care Center (NAI);

- Carry out health promotion activities for caregivers with open themes in question format, allowing the possibility of listening to their demands.

- Perform external social activities.

Figure 1. The action plan. 
Os próprios participantes, ao discutir o plano de ação, se preocuparam em:

Item I refers to the importance of listening to the demands of the group. In item II, inter-consultations are where professionals from different categories perform a service together. In the outpatient consultations, and instead they are scheduled according to the organization of the team for specific cases. The nurses believe this strategy optimizes time and strengthens the professional group. In item III, the group reports that the consultation will therefore be more resolutive and adhesion easier to achieve. Item IV refers to moving away from the "policing" posture of return appointments, whether the person has been able to implement certain advice and help in relation to the difficulty the user is experiencing or not. There will be cases where it will be necessary to make adaptations and negotiate, and also to celebrate what has been achieved. In item $\mathrm{V}$, co-responsibility is a consequence of participation in the therapeutic plan. Item VI means to negotiate between the professionals of the outpatient clinic and with the public health policies for the elderly. Item VII refers to a way to limit divergences. Item VIII involves performing activities of cognitive stimulation and day-center activities; in this case, it would satisfy the requests of caregivers to have an activity in which they can bring the elderly for stimulation. In Item IX, both caregivers and nurses recognized the need to talk about care in a gentler way. In item $\mathrm{X}$, the nurses expressed the desire to expand the activities to other professionals who are not necessarily in the health area. Finally, item XI approximates the understanding that the Elderly Care Center can be a space for health promotion, in its broadest sense, not only providing direct care or education, but also establishing moments of exchange, leisure and the strengthening of bonds.

As a contribution to the practice of care, the present study demonstrated that difficulties are part of the life of the family caregiver. With this knowledge, health professionals should understand that they will suffer moments of burden, anxiety and even want to avoid the responsibility of care, but also that this is part of

a process. Caregiver who provide an ideal, firmlyestablished, unshakable, disciplined, and "standard" approach do not always produce better care.

Health professionals should advise families that there is no ideal caregiver profile, as each caregiver tends to deal with critical situations differently. Thus, demanding standard behavior only causes distress, and leads to unnecessary burden.

One limitation of this study is that the location of the research is one of the few referral centers for the health of the elderly in the state of Rio de Janeiro. In other words, although the results point out several contradictions, they may not constitute the true picture of the difficulties encountered by those who lack even the access to a referral service. Therefore, the study showed that the income and high degree of schooling of the participants did not exempt them from the difficulties related to care. Thus, the results of the study may be different if the social context of the group of participants is modified.

\section{CONCLUSION}

The aim of the present study was to analyze a proposal for an action plan elaborated by nurses to tackle the contradictions in the care process of the elderly. This objective has been fully achieved. It was also possible to reveal the difficulties encountered by family caregivers in the process of caring for the elderly and to discuss the actions of nurses in coping with problems experienced by family caregivers of the elderly.

It was found that care for the elderly is socially produced. Health issues must therefore be understood beyond the problems of illness, as disease is only the consequence, the clinical manifestation, and the result of what has been produced by society. The difficulties most frequently described in the discourse of the participants were: the dilemma over caring for oneself while caring for another, the confrontation between the caregiver and the elderly, the conflict between the primary caregiver and other family 
members, and the contradiction between public policies and reality.

Therefore, nurses recognize their ability to receive, listen to and manage the demands of family caregivers of the elderly and promote the health of the elderly and caregivers when preparing them for home care.

\section{ACKNOWLEDGEMENTS}

The authors would like to thank Nurse Ivone Renor da Silva Conceição, chief nurse of the outpatient clinic of the Geriatric Care Center for the Elderly, for facilitating data collection and contributing suggestions for workshops.

\section{REFERENCES}

1. Pinto JBN. Hacia una pedagogia de liberación. In: Duque-Arrazola LS, Thiollent MJM, organizadores. Metodologia, teoria do conhecimento e pesquisa-ação: Textos selecionados e apresentados. Belém: UFPA; 2014. p.156-8.

2. David HMSL, Bonetti OP, Silva MRF. A Enfermagem brasileira e a democratização da saúde: notas sobre a Política Nacional de Educação Popular em Saúde. Rev Bras Enferm. 2012;65(1):179-85.

3. Krieger N, Davey SG. FACEing reality: productive tensions between our epidemiological questions, methods and mission. Int J Epidemiol. 2016;45(6):1852-65.

4. Vieira Junior WM, Martins M. Idosos e planos de saúde no Brasil: análise das reclamações recebidas pela Agência Nacional de Saúde Suplementar. Ciênc. Saúde Colet. 2015;20(2):3817-26.

5. Seima MD, Lenardt MH, Caldas CP. Relação no cuidado entre o cuidador familiar e o idoso com Alzheimer. Rev Bras Enferm. 2014;67(2):233-40.

6. Cupidi C, Realmuto S, Lo Coco G, Cinturino A, Talamanca S, Arnao V, et al. Sleep quality in caregivers of patients with Alzheimer's disease and Parkinson's disease and its relationship to quality of life. Int Psychogeriatr. 2012;24(11):1827-35.

7. Pope T. How person-centred can improve nurses atitudes to hospitalised older patients. Nurs Older Peopl. 2012;24(1):32-7.

8. Rocha PR, David HMSL. Determination or determinants?: a debate based on the Theory on the Social Production of Health. Rev Esc Enferm USP. 2015;49(1):127-33.

9. Grillo GPM, Marins AMF, Melo R. O discurso do cuidador familiar sobre a hospitalização. Rev Pesqui Cuid Fundam (online). 2017;9(4):1068-73.

10. Vieira SL, Almeida FM. Equidade em saúde, uma análise crítica de conceito. Cad Saúde Pública. 2009;25(2):5217-26.
11. Moore S, Kawachi I. Twenty years of social capital and health research: a glossary. J Epidemiol Community Health. 2017;71(5):513-17.

12. Mendes R, Pezzato LM, Sacardo DP. Pesquisaintervenção em promoção da saúde: desafios metodológicos de pesquisar “com”. Ciênc Saúde Coletiva. 2016;21(6):1737-45.

13. Thiollent MJM, Toledo RF. Participatory methodology and action research in the area of health. Int J Action Res. 2012;8(2):142-58.

14. Bardin L. Análise de conteúdo. Lisboa: Edições 70; 2011.

15. Brasil. Conselho Nacional de Saúde. Resolução no 466 de 12 de dezembro de 2012, Aprova as diretrizes e normas regulamentadoras de pesquisas envolvendo seres humanos 2013. Diário Oficial da União. 13 jun. 2013.

16. David HMSL, Progianti JM. Enfermagem hoje: viver menos para trabalhar mais? Brasil.Rev Enferm UERJ. 2011;19(3):351-52.

17. Longhi JC, Canton GAM. Reflexões sobre cidadania e os entraves para a participação popular no SUS. Physis. 2011;21(1):15-30.

18. Barata RB. Saúde nas grandes metrópoles e populações socialmente vulneráveis. Rev USP. 2015;107:27-42.

19. Barros MEB, Roza MMR, Guedes CR, Oliveira GN. O apoio institucional como dispositivo para a implantação do acolhimento nos serviços de saúde. Interface (Botucatu). 2014;18(1):1107-17.

20. Jankelevitch V. La mort. Paris: Flammarion; 2008.

21. Souza HS, Mendes A. Trabalho \& Saúde no capitalismo contemporâneo: enfermagem em foco. São Paulo: Doc; 2016.

22. Pereira LSM, Soares SM. Fatores que influenciam a qualidade de vida do cuidador familiar do idoso com demência. Ciênc Saúde Coletiva. 2015; 20(12):3839-51. 